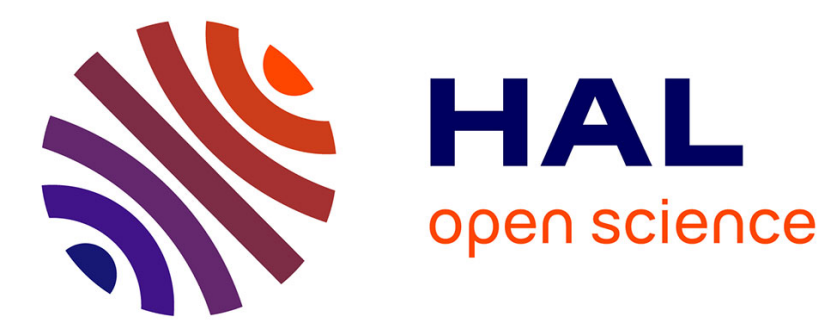

\title{
Gesture recognition with the chipless RIFD technology
}

Nicolas Barbot, Etienne Perret

\section{To cite this version:}

Nicolas Barbot, Etienne Perret. Gesture recognition with the chipless RIFD technology. 2017 XXXIInd General Assembly and Scientific Symposium of the International Union of Radio Science (URSI GASS), Aug 2017, Montreal, Canada. pp.19 - 26, 10.23919/URSIGASS.2017.8104990 . hal-01944690

\section{HAL Id: hal-01944690 \\ https://hal.univ-grenoble-alpes.fr/hal-01944690}

Submitted on 1 Jul 2020

HAL is a multi-disciplinary open access archive for the deposit and dissemination of scientific research documents, whether they are published or not. The documents may come from teaching and research institutions in France or abroad, or from public or private research centers.
L'archive ouverte pluridisciplinaire HAL, est destinée au dépôt et à la diffusion de documents scientifiques de niveau recherche, publiés ou non, émanant des établissements d'enseignement et de recherche français ou étrangers, des laboratoires publics ou privés. 


\title{
Gesture recognition with the chipless RIFD technology
}

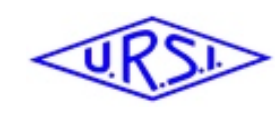

\author{
Nicolas Barbot ${ }^{(1)}$, Etienne Perret $^{(1,2)}$ \\ (1) University of Grenoble Alpes, LCIS, Valence \\ (2) Institut Universitaire de France, Paris, France
}

\begin{abstract}
In this paper, we show that the chipless RFID tag can be used as a sensor to detect the presence of a user finger on the tag and also to locate the position of the finger on this tag. These results point the way toward new kind of human-computer interactions based on gesture recognition which can be contactless and 3D.
\end{abstract}

\section{Introduction}

Human-computer interactions (HCI) are classically based on physical contact between the user and the device. For example a smartphone can be controlled by using the touchscreen with a finger. This physical contact directly impacts the size of the device used to interact with the user. Moreover, despite of microelectronic advances, this size cannot be decreased without reducing user experience.

In this paper, we propose a new 3D HCI based on the use of the chipless RFID technology. Our system can detect the specific user gesture like the position of the finger on a tag's surface. The chipless tag, potentially realized on paper with inkjet printer plays the role of a remote control but without any electronic component. Indeed, since our architecture is based on a chipless tag, the system is entirely passive and need no battery [1]. Thinks to the radar approach used in chipless, lot of accurate information can be deduced form that type of reading. For example it is possible to extract any displacement of the label with submillimeter precision [2]. So as it is possible to measure in real time the position of the tag (the distance between the tag and the reader, but also lot of other information that some of them will be introduced in that paper), gesture recognition can be done. Moreover the identification function of the RFID tag is still available in the signature and can be used to separate various users.

Contactless human-computer interactions using electromagnetic waves have already been investigated in the literature. Soli project is developed by Google ATAP since 2015 [3]. This project is based on an integrated millimeter radar able to detect slight variations in its vicinity and track human hand motion. This radar operates at $60 \mathrm{GHz}$ and realizes more than 10000 acquisitions per second. Compared to Soli project, our solution operates in UWB band and uses RFID tag to isolate the user interaction form the environment (which can be nonstationary). The WISP (Wireless Identification and
Sensing Platform) is another project which can realize contactless HCI [4]. This platform is based on the use of a low power microcontroller coupled with sensors. The whole system can be powered by standard RFID reader and can communicate using backscatter modulation. Unlike WISP, our solution proposes a simple chipless tag to sense the environment. However, useful information has to be extracted from the backscattered signal, as for a radar target designed to be able to sense it direct environment.

The paper is organized as follow: Section 2 presents the chipless RFID technology and describes the principle of sensing with a classical chipless RFID tag. Section 3 presents the results of our study. Conclusion is finally exposed in the last section.

\section{Chipless tag}

Chipless RFID technology is closely related to radar technology [1]. The principle relies on generating a pulse toward the RFID tag, and receiving a signature which depends on the characteristics of the tag. Chipless tag can be composed with different resonators [5]. Resonance frequencies are classically used to uniquely identify a tag. However, the resonance frequency $f_{r}$ of a given resonator does not only depend on geometrical dimensions, typically like the length $L$ of the resonator. This can be seen with the following general formula:

$$
f_{r}=\frac{c}{4 L \sqrt{\overline{\varepsilon_{e f}}}}
$$

Where $\varepsilon_{e f}$ is the effective permittivity of the device which depends on various parameters including the presence of dielectric medium placed in proximity of the resonator that directly affects the electric field distribution. Thus, if a modification in the tag environment is considered, the value of $\varepsilon_{e f}$ can be affected which imply a modification in the resonance frequency.

In the proposed solution, this property is used to detect the presence of a modification in the tag environment (presence or absence of the user digit) and also to locate the position of the finger. To show the potential of this technology to achieve gesture recognition application, classical RFID chipless tags operating in cross polarization and composed of 6 resonators have been used [6]. Resonators are placed in a row and separated by 1.5 $\mathrm{cm}$. Figure 1 presents the tag used for the application. 


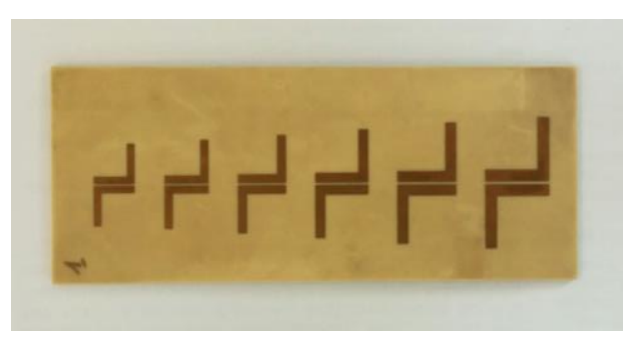

Figure 1. Chipless RFID tag used for gesture recognisation.

Fig. 2 shows the measurement bench used inside an anechoic chamber. The dual-access dual-polarization Satimo QH2000 antenna is connected to the VNA ports 1 and 2 in the horizontal and vertical polarization, respectively. Fig. 3 shows the raw signal in frequency domain then transformed in time domain. Time filtering approaches to remove structural mode are applied. Figure 3 shows the results obtained before and after filtering. The 6 resonance frequencies corresponding to the 6 resonators can be seen after the filtering without ambiguity.

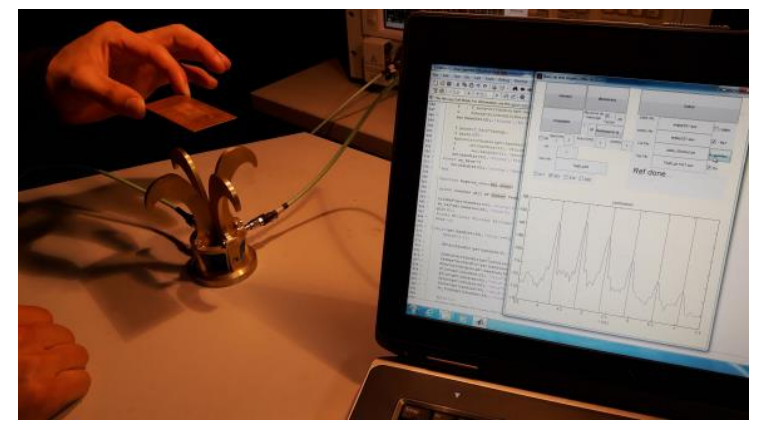

Figure 2. Measurement bench used in an anechoic chamber for gesture recognition measurements.
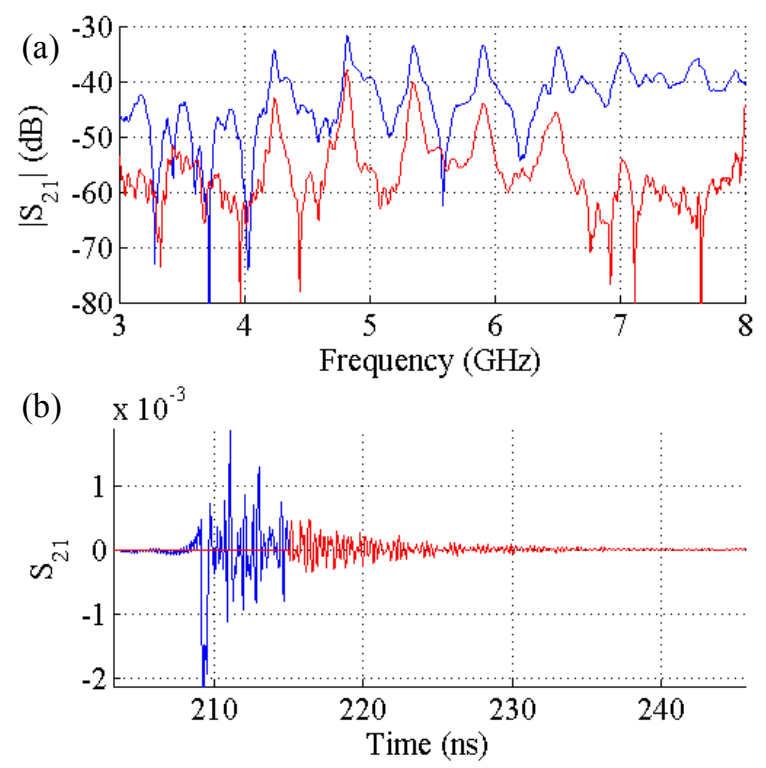

Figure 3. Measured backscatered signal of the chipless tag presented Fig. 1 : raw signal (in blue) and after time window filtering (in red). a) Frequency and, b) time domaine signal.
The idea is to see how these resonance frequencies are affected by the presence of any interaction between a user and the label. Indeed, our goal is to detect the presence of the user hand / finger on the tag. More precisely, as shown Fig. 4, we want to determine the position of the finger on the chipless tag from real time RCS measurements.

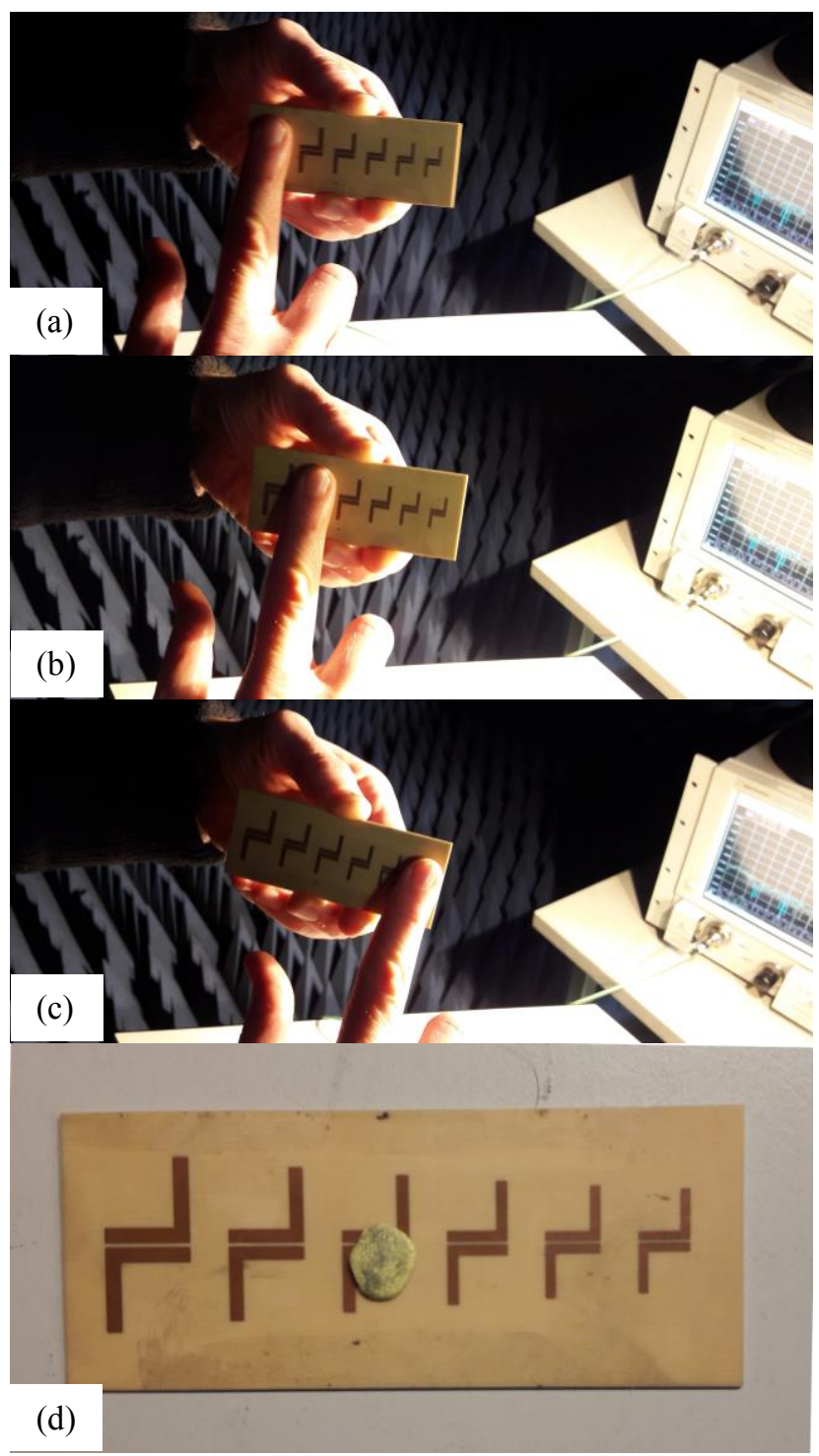

Figure 4. a)- b)- c) Different positions of the finger on the top of the chipless tag. d) Configuration using a dielectric paste localised on one resonator.

\section{Results}

We began our study by showing the impact of a tiny modification of the resonator environment by placing a little quantity of dielectric paste on a single resonator. Fig. 4.d presents the practical configuration and the measurement results are plotted Fig. 5. 


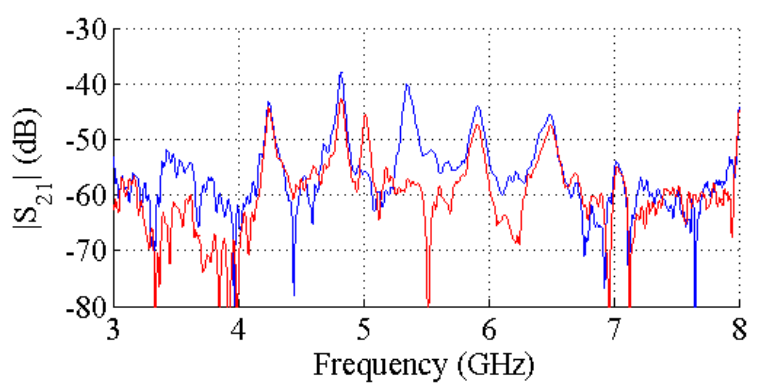

Figure 5. Response of the tag without dielectric paste (in blue) and with (in red).

We can clearly see that one resonance frequency (the one where the paste has been added - see Fig. 4.d) is shifted whereas the others are not affected. We observe a reduction of the frequency for the third resonator which means the effective permittivity $\varepsilon_{e f}$ corresponding to it has been modified [increased in this case - see (1)]. We also observe that the resonance frequencies of the others are identical. The same behavior for all resonators has been observed.
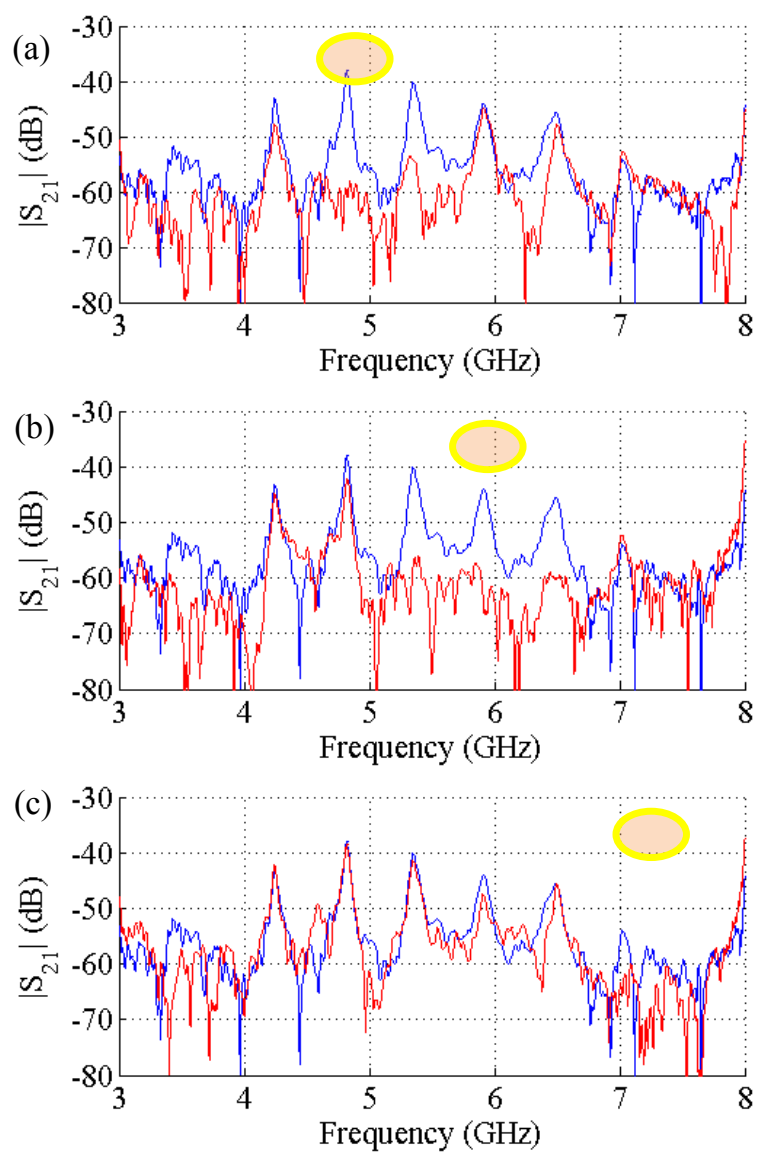

Figure 6. Response of the tag without finger (in blue) and with finger (in red) for three different positions of the finger (as illustrated Fig. 4.a.b.c). The finger's position is symbolysed by yelow circles.
We now want to show the impact of a finger on the tag's response. For this, the same experimentation has been done with a finger as shown in Fig. 4.a.b.c. Fig 6 shows the measurement results when the user places a finger on the second, fourth and sixth resonator. We can see that the presence of the finger implies an increase of the permittivity value which remove the corresponding peak. Similar results have been obtained for all resonators. Moreover, all measurements have been realized in real time (processing time is lower than $10 \mathrm{~ms}$ ). Since this time is significantly smaller than the travel time between tow resonators our approach can permit identifying more complex movements. For example, machine learning also can be useful in this case to classify and recognize new movements.

\section{Conclusion}

In this paper, we have shown that we can use a chipless RFID tag as a sensor to locate the position of the finger on the tag. Moreover our approach can be applied to paper tags where tags can be used as an ultra-low cost remote control. These results point the way toward new kind of human-computer interactions.

\section{References}

[1] A. Vena, E. Perret, and S. Tedjini, Chipless RFID based on RF Encoding Particle - Realization, Coding and Reading System: ISTE - Elsevier, 2016.

[2] E. Perret, "Displacement Sensor Based on Radar Cross-Polarization Measurements," IEEE Transactions on Microwave Theory and Techniques, vol. PP, pp. 1-12, 2017.

[3] J. Lien, N. Gillian, M. E. Karagozler, P. Amihood, C. Schwesig, E. Olson, H. Raja, and I. Poupyrev, "Soli: ubiquitous gesture sensing with millimeter wave radar," J ACM Trans. Graph., vol. 35, pp. 1-19, 2016.

[4] A. P. Sample, D. J. Yeager, P. S. Powledge, A. V. Mamishev, and J. R. Smith, "Design of an RFID-Based Battery-Free Programmable Sensing Platform," IEEE Transactions on Instrumentation and Measurement, vol. 57, pp. 2608-2615, 2008.

[5] A. Vena, E. Perret, and S. Tedjini, "Chipless RFID tag using hybrid coding technique," IEEE Transactions on Microwave Theory and Techniques, vol. 59, pp. 3356-3364, 2011.

[6] A. Vena, E. Perret, and S. Tedjini, "A Depolarizing Chipless RFID Tag for Robust Detection and Its FCC Compliant UWB Reading System," IEEE Transactions on Microwave Theory and Techniques, vol. 61, pp. 2982 - 2994, 2013. 